\title{
Heart age estimated using explainable advanced electrocardiography
} Thomas Lindow, MD, PhD ${ }^{1,2,3^{*}}$, Israel Palencia-Lamela, ${ }^{1,4^{*}}$ Todd T Schlegel, MD ${ }^{5,6}$, Martin Ugander, MD, $\mathrm{PhD}^{1,5}$

1. Kolling Institute, Royal North Shore Hospital, and University of Sydney, Sydney, Australia

2. Department of Clinical Physiology, Research and Development, Växjö Central Hospital, Region Kronoberg, Sweden

3. Clinical Physiology, Clinical Sciences, Lund University, Sweden

4. Davidson College, Davidson, North Carolina, USA

5. Department of Clinical Physiology, Karolinska Institutet, and Karolinska University Hospital, Stockholm, Sweden

6. Nicollier-Schlegel SARL, Trélex, Switzerland

\section{*Shared first-authorship by equal contribution}

Fundings: TL is currently under the support of postdoctoral research grants from The Swedish Heart-Lung Foundation (grant no 20200553), the Swedish Cardiac Society, the Royal Swedish Academy of Sciences (grant no LM2019-0013), Women and Health Foundation, Region Kronoberg (grant no 8301), The Swedish Heart and Lung Association (grant no LKH1387), Swedish Association of Clinical Physiology, and the Scandinavian Society of Clinical Physiology; Nuclear Medicine. The study was funded in part by grants (PI Ugander) from New South Wales Health, Heart Research Australia, and the University of Sydney.

Author contributions: TL and IPL contributed to study design, performed the data analysis, wrote the first manuscript drafts, prepared the figures, and are shared first authors by equal contributions. TTS curated the data, contributed to study design, performed the prediction modeling, and critically revised the manuscript. MU designed the study, provided supervision, and critically revised the manuscript. All authors read and approved the final version of the manuscript.

\section{Competing interests:}

TL, IPL: None

TTS is owner and founder of Nicollier-Schlegel SARL, which performs ECG interpretation consultancy using software that can quantify the advanced ECG measures used in the current study. TTS and MU are owners and founders of Advanced ECG Systems, a company that is developing commercial applications of advanced ECG technology used in the current study.

Corresponding author: Martin Ugander, martin.ugander@ki.se, Professor of Cardiac Imaging, University of Sydney, Sydney, Australia, and Karolinska Institute, Sweden. 
39 Background: Electrocardiographic (ECG) Heart Age conveying cardiovascular risk has been

40 estimated by both Bayesian and artificial intelligence approaches. We hypothesized that

41 explainable measures from the 10-second 12-lead ECG could successfully predict Bayesian

42 ECG Heart Age.

43 Methods: Advanced analysis was performed on ECGs from healthy subjects and patients

44 with cardiovascular risk or proven heart disease. Regression models were used to predict a

45 Bayesian 5-minute ECG Heart Age from the standard resting 10-second 12-lead ECG. The difference between 10-second ECG Heart Age and chronological age was compared.

Results: In total, 2,771 subjects were included ( $n=1682$ healthy volunteers, $n=305$ with cardiovascular risk factors, $n=784$ with cardiovascular disease). Overall, 10-second Heart Age showed strong agreement with the 5-minute Heart Age $\left(R^{2}=0.94, p<0.001\right.$, mean $\pm S D$ bias 0.0 \pm 5.1 years). The difference between 10-second ECG Heart Age and chronological age was $0.0 \pm 5.7$ years in healthy individuals, $7.4 \pm 7.3$ years in subjects with cardiovascular risk factors $(\mathrm{p}<0.001)$, and 14.3 \pm 9.2 years for patients with cardiovascular disease $(\mathrm{p}<0.001)$.

Conclusions: ECG Heart Age can be accurately estimated from a 10-second 12-lead ECG in a transparent and explainable fashion based on known ECG measures, without artificial intelligence techniques. The difference between ECG Heart Age and chronological age increases markedly with cardiovascular risk and disease.

Keywords: vascular age; electrocardiography cardiovascular risk prediction; advanced electrocardiography; vectorcardiography 


\section{Background}

62 Cardiovascular disease is a significant contributor to mortality, and pathological processes

63 begin early and can progress silently for many years ${ }^{1-3}$. Many of the risk factors for

64 developing cardiovascular disease are lifestyle-related ${ }^{4}$. Fortunately, several of these are

65 modifiable, and risk can therefore be reduced for example by smoking cessation, dietary

66 changes and increased physical activity ${ }^{5,6}$. To accomplish this, an individual must fully

67 understand their risk and become motivated to act upon it. One way of communicating risks to the patient is to present the risk as a "Heart Age", which can be contrasted to the patient's chronological age. A Heart Age can either be determined by translating risk factor scores to what age that score would represent in an individual with no risk factors, or it can be based on electrocardiographic changes ${ }^{7-12}$. Describing the risk to the patient using Heart Age has been reported to reduce metabolic risk factors and may have the advantage of being easily understood by the patient ${ }^{11,13}$. A similar approach has been applied when conveying risk to smokers by describing how 'old' their lungs are, and such an approach increased the chance of smoking cessation ${ }^{14}$.

Moving beyond but not excluding basic ECG measurements such as heart rate and waveform amplitudes and durations, the diagnostic output from the ECG can be further substantially improved by using combinations of advanced ECG measures from 12-lead-ECG-derived vectorcardiography and waveform complexity ${ }^{15-17}$. An accurate ECG Heart Age using advanced, 5-minute, 12-lead ECG was developed in 2014, based on Bayesian statistics ${ }^{9}$. The Bayesian approach was transparent in so much as the advanced ECG measures contributing to the ECG Heart Age were well-described. After being trained on a set of healthy individuals, this approach yielded increased ECG Heart Ages for subjects at risk of cardiovascular disease and even higher ECG Heart Ages for those with established cardiovascular disease ${ }^{9}$. 
likelihood of widespread clinical use. If standard 10-second ECG recordings could be used instead, the clinical impact might be enhanced. Moreover, artificial intelligence has been used to estimate ECG Heart Age using the 10 -second resting 12-lead ECG ${ }^{7,8,10}$. However, artificial intelligence techniques are limited by their "black box" approach, whereby the clinician does not have transparency as to the exact source(s) of the changes in the ECG that can affect an ECG Heart Age or other output ${ }^{18,19}$. Therefore, the aim of the study was to predict 5-minute ECG Heart Age from measures available by 10-second 12-lead ECG, and to compare the 10second ECG Heart Age to chronological age in healthy subjects, subjects with cardiovascular risk factors, and patients with established cardiovascular disease. We hypothesized that 10second 12-lead ECG recordings could accurately predict Bayesian ECG Heart Ages derived from 5-minute 12-lead ECG recordings.

\section{Methods}

A database of de-identified patients with both 5-minute and 10-second 12-lead ECG recordings was utilized for the study ${ }^{9}$. Within that database, healthy individuals, patients at cardiovascular risk, and patients with established cardiovascular disease were included. All healthy subjects were low-risk asymptomatic volunteers with absence of any cardiovascular or systemic disease, based on clinical history and physical examination. Exclusion criteria for the healthy subjects included increased blood pressure at physical examination $(\geq 140 / 90 \mathrm{~mm}$ $\mathrm{Hg}$ ), treatment for hypertension or diabetes, or active smoking. Patients with established cardiovascular disease were included based on the presence of either coronary heart disease (determined by coronary angiography with at least one obstructed vessel ( $\geq 50 \%)$ in at least one major native coronary vessel or coronary graft, or, if coronary angiography was either unavailable or clinically not indicated, one or more reversible perfusion defects on 99m-Tctetrofosmin single-photon emission computed tomography $\left(\right.$ SPECT) ${ }^{20-22}$ ), left ventricular 
111 hypertrophy (LVH) based on imaging evidence of at least moderate, concentric wall

112 thickening according to guidelines of the American Society of Echocardiography ${ }^{23}$, left

113 systolic dysfunction (left ventricular ejection fraction $\leq 50 \%$ ) at echocardiography, cardiac

114 magnetic resonance imaging (CMR) or SPECT, or findings suggestive of

115 dilated/hypertrophic/ischemic cardiomyopathy at echocardiography or CMR ${ }^{16}$. Finally,

116 subjects at cardiovascular risk were included based on the presence of cardiovascular risk

117 factors such as hypertension or diabetes but no confirmed established cardiovascular disease ${ }^{9}$.

118 Based on the above, three groups of study participants were included: healthy subjects,

119 subjects at cardiovascular risk, and patients with established cardiovascular disease. By

120 methodological design, onlyhealthy subjectswere initially included when considering optimal

121 measures of ECG available from 10-second 12-lead ECG for predicting the 5-minute ECG

122 Heart Age. The 10-second ECG measures considered for the prediction model included: (1)

123 From the conventional ECG: heart rate, R-to-R, P-wave, PR, QRS, QT, QTc, and TQ interval

124 durations, as well as the conventional ECG amplitudes and axes; (2) From the transformation

125 of the 12-lead ECG to the Frank X, Y and Z lead vectorcardiogram (VCG) via Kors'

126 transform ${ }^{24-28}$ : the spatial means and peaks QRS-T angles, the spatial ventricular gradient and

127 its individual QRS and T components, the spatial QRS- and T-wave axes (azimuths and

128 elevations), waveform amplitudes and areas, including those in the three individual

129 vectorcardiographic planes, and spatial QRS-and T-wave velocities; and (3) measures of

130 QRS-and T-wave waveform complexity based on singular value decomposition after signal

131 averaging ${ }^{29-31}$.

132 For all study participants, the difference between the 10-second ECG Heart Age and the

133 chronological age was also calculated. Results were then compared between the three groups

134 defined above. All participants gave written informed consent. All recordings were obtained

135 under Institutional Review Board (IRB) approvals from NASA's Johnson Space Center and 
medRxiv preprint doi: https://doi.org/10.1101/2021.12.08.21267378; this version posted December 8, 2021. The copyright holder for this preprint (which was not certified by peer review) is the author/funder, who has granted medRxiv a license to display the preprint in perpetuity.

All rights reserved. No reuse allowed without permission.

136 partner hospitals that fall under IRB exemptions for previously collected and de-identified

137 data. The study was performed in accordance with the Declaration of Helsinki.

139 Continuous variables were described using mean and standard deviation (SD). The chi-

140 squared test was used to test for proportional differences between groups. Student's $t$ test was

141 used to compare group means. The 10-second ECG Heart Age was first derived only in the

142 healthy subject group through a process of feature selection, via optimized stepwise

143 procedures, of measures available from 10-s, standard-fidelity ECG recordings, first using

144 univariable linear regression, and finally as multivariable linear regression, to best predict the

145 5-minute ECG Heart Age ${ }^{9}$. The best model was defined as the model with highest $\mathrm{R}^{2}$ value

146 that was also the most parsimonious, i.e., a model with statistically equal performance that

147 incorporated a lesser number of measures was considered more parsimonious due to less

148 proneness to over-fitting. The best model from the healthy volunteers was then applied

149 forward to an expanded population that also included the other two groups (cardiovascular

150 risk and cardiovascular disease, respectively), while not changing any of the included

151 variables, and only allowing optimization of the included coefficients. The final sex-specific

152 model was then applied across all three groups as the 10-secondECG Heart Age, and

153 comparisons with 5-minute ECG Heart Age are presented as scatter plots and Bland-Altman

154 plots. A two-sided p-value of 0.05 was used as to define statistical significance. Statistical

155 analyses were performed using SAS JMP version 11.0, SAS Institute Inc, Cary, NC, USA,

156 and R version 3.5.3R, R Foundation for Statistical Computing, Vienna, Austria, 
medRxiv preprint doi: https://doi.org/10.1101/2021.12.08.21267378; this version posted December 8, 2021. The copyright holder for this preprint (which was not certified by peer review) is the author/funder, who has granted medRxiv a license to display the preprint in perpetuity.

All rights reserved. No reuse allowed without permission.

160

161

162

163

164

\section{Results}

In total, 2,771 patients were included ( $\mathrm{n}=1682$ healthy volunteers, $\mathrm{n}=305$ subjects with cardiovascular risk factors, $\mathrm{n}=784$ with cardiovascular disease). Baseline characteristics are presented in Table 1. The ECG measures included in the final prediction models are presented in Table 2 (males) and Table 3 (females).

The 10-second ECG Heart Age showed excellent agreement with the 5-minute Heart Age $\left(\mathrm{R}^{2}=0.94, \mathrm{p}<0.001\right.$, mean $\pm \mathrm{SD}$ bias $0.0 \pm 5.2$ years $)$, Figure 1 . Agreement was strong for both males and females $\left(\mathrm{R}^{2}=0.91, \mathrm{p}<0.001\right.$, and $\mathrm{R}^{2}=0.92, \mathrm{p}<0.001$ respectively). In healthy subjects, there was no difference in ECG Heart Age and chronological age (0.0 \pm 5.7 years). In subjects with cardiovascular risk factors, the difference was higher $(7.4 \pm 7.3$ years, $\mathrm{p}<0.001)$. Patients with cardiovascular disease showed the largest difference between ECG Heart Age and chronological age $(14.3 \pm 9.2$ years, $\mathrm{p}<0.001$ when compared to subjects at cardiovascular risk), Figure 2.

\section{Discussion}

We found that ECG Heart Age based on measures of advanced ECG can be accurately predicted from standard resting 10-second 12-lead ECG recordings. This facilitates widespread use of ECG Heart Age in routine clinical settings, since neither specialized ECG machines nor unusually lengthy recordings are necessary. Also, if digital ECG raw data are available and the recording is of acceptable quality, ECG Heart Age can be retrospectively determined. Further, we found ECG Heart Age to be similar to chronological age in healthy individuals, while the ECG Heart Age was increasingly older with increasing cardiovascular disease status. This suggests that the ECG Heart Age is likely to provide accurate cardiovascular risk prediction, although validation in other datasets is necessary. 


\section{Explainability and transparency of variables that contribute to ECG Heart Age}

185 For an estimation of Heart Age to be accurate in predicting an age that is similar to the chronological age when the heart is healthy, and increased when the heart is diseased, it is desirable that the included ECG measures change with age, and that the change is augmented with increasing cardiovascular risk or disease severity. Beyond age itself, the two ECG measures that had the strongest influence (highest $\mathrm{t}$ ratio) on the model were P-wave duration and spatial QT duration, and these measures fit this description well. P-wave duration increases with age ${ }^{32}$, and increased P-wave duration can be seen in advanced cardiovascular pathologies, e.g. heart failure and cardiac amyloidosis ${ }^{33}$. Similarly, QT duration increases with age ${ }^{34}$. Further, QT prolongation is associated with increased of cardiovascular risk, even beyond the rare long QT syndromes ${ }^{35}$, and with incrementally increased risk in advanced ages $^{36}$. These general characteristics are also true for increased heart rate and for leftward shifting of the frontal plane QRS axis ${ }^{37-40}$. The other measures included in the score track changes in the vectorcardiographic QRS and T, and in T-wave complexity by singular value decomposition. Such changes are also known to occur in conditions associated with increased cardiovascular risk, such as hypertension and diabetes ${ }^{41}$, and in established cardiovascular disease, in which they often provide strong diagnostic and prognostic information ${ }^{24-27,29-31}$. Notably, these changes are not easily detectable by visual interpretation of a standard 12-lead ECG. How these ECG measures can affect the ECG Heart Age is exemplified in Figure 3. Taken together, the described ECG measures that contribute in a multivariable fashion to the ECG Heart Age all have physiologically reasonable associations with age and disease in a way that is transparent to the assessing clinician, thus providing important explainability to the model. 
Differences compared to Bayesian 5-minute ECG Heart Age

210 The original, Bayesian 5-minute ECG Heart Age requires information from measures of beat-

211 to-beat heart rate and QT variability, ${ }^{9}$ and of the root-mean square voltage or other aspects of

212 high-frequency (high fidelity) components of the QRS complex ${ }^{42-44}$. However, 10-second-

213 duration recordings of standard fidelity do not allow for such measures, and therefore they

214 were not included in the 10-second ECG Heart Age. However, unlike the original Bayesian 5-

215 minute ECG Heart Age, the 10-second ECG Heart Age should be derivable from any standard

216 12-lead ECG machine, as long as it is sufficiently equipped with software that can measure

217 the included measures and calculate the 10-second ECG Heart Age. The presented 10-second

218 ECG Heart Age might therefore be anticipated to contribute to more widespread clinical

219 penetration and use.

Comparison with other Heart (or Vascular) Ages

Different means of expressing cardiovascular risk by translating it into a heart or vascular age have recently been published ${ }^{13}$. Attia, et al, showed that by using a deep neural network (DNN) artificial intelligence (AI) technique, a patient's chronological age could be predicted, and that if the difference between the predicted and actual age was small, prognosis was good

${ }^{8}$. When Heart Age by Attia et al's technique was older than the chronological age, the risk of future death was increased ${ }^{7}$. This corresponds well to the findings in our study that ECG Heart Age increased with increasing burden of cardiovascular risk. However, the prognostic value of the ECG Heart Age presented in the current study requires additional validation. Furthermore, another AI method similar to that of Attia et al reported similarly encouraging

231 results $^{10}$. However, although the results of such AI studies are promising, DNN-based AI 232 techniques are inherently problematic in several respects, especially in relation to their lack of 233 transparency and explainability, i.e., the 'black box' of $\mathrm{AI}^{18,19}$. Without the ability to know the 
medRxiv preprint doi: https://doi.org/10.1101/2021.12.08.21267378; this version posted December 8, 2021. The copyright holder for this preprint (which was not certified by peer review) is the author/funder, who has granted medRxiv a license to display the preprint in perpetuity.

All rights reserved. No reuse allowed without permission.

exact features of the 12-lead ECG that are most important in a given DNN model's output, both interpretability and ethical accountability are compromised ${ }^{45}$. Moreover, it is effectively impossible for a clinician to identify, when critically evaluating the diagnostic output of a DNN-based AI model, the possible contribution to the result from methodological artifact or bias merely related to noise or to differing technical specifications between different ECG machines ${ }^{46}$. Alternatively, it is not possible to know if unanticipated results are possibly just related to excess dependency on the particular characteristics of a given DNN AI model's training set ${ }^{47}$. In addition, a major flaw in both DNN-based AI models is that the age predictions were made using datasets including individuals with both cardiovascular risk factors and established disease ${ }^{8,10}$. For ECG Heart Age to be used as a marker of cardiovascular risk, it is imperative that ECG Heart Age agrees with chronological age in healthy populations, since it is the deviations from the line of identity in this relationship that form the basis of the assumed risk increase ${ }^{8}$.

Hence, we believe that the pursuit of an ECG Heart Age developed from heart-healthy subjects of varying ages, but without a black-box DNN or related AI methodology is valuable, and that the present results provide sufficient confirmation of accuracy to encourage further development. In addition, models in which the assessments were based on age predictions in healthy subjects will likely outperform models that were not. And finally, the use of more transparent regression models will also increase the ability of clinicians to better understand the origin of any unexpected result, and to thereafter relay it to the patient with a more convincing sense of trust and ethical accountability ${ }^{45}$.

\section{Limitations}

Using the same dataset for training and validation, our results can only be considered as proof-of-concept. Although the difference between ECG Heart Age and the subjects' 
medRxiv preprint doi: https://doi.org/10.1101/2021.12.08.21267378; this version posted December 8, 2021. The copyright holder for this preprint

(which was not certified by peer review) is the author/funder, who has granted medRxiv a license to display the preprint in perpetuity.

All rights reserved. No reuse allowed without permission.

259 chronological age increased with increasing cardiovascular risk and/or disease, the prognostic

260 value is unknown. Also, although ECG Heart Age was highly accurate, the precision cannot

261 be reliably defined in this study. These aspects therefore need to be addressed in future

262 studies.

263

264 Conclusion

265 We show that ECG Heart Age can be accurately, transparently, and explainably estimated

266 from a standard 10-s, resting 12-lead ECG utilizing multiple, discrete conventional and

267 advanced ECG measures. The difference between ECG Heart Age and subjects'

268 chronological age increases with increasing cardiovascular risk and disease. The prognostic

269 value of our transparent and explainable 10-second ECG Heart Age requires prospective

270 evaluation in future studies.

271

272 
medRxiv preprint doi: https://doi.org/10.1101/2021.12.08.21267378; this version posted December 8, 2021. The copyright holder for this preprint (which was not certified by peer review) is the author/funder, who has granted medRxiv a license to display the preprint in perpetuity.

All rights reserved. No reuse allowed without permission.

273

274

275

276

277

278

279

280

281

282

283

284

285

286

287

288

289

290

291

292

293

294

295

\section{References}

1 Bergström, G. et al. Prevalence of Subclinical Coronary Artery Atherosclerosis in the General Population. Circulation 144, 916-929, doi:10.1161/circulationaha.121.055340 (2021).

Townsend, N. et al. Cardiovascular disease in Europe: epidemiological update 2016. Eur Heart J 37, 3232-3245, doi:10.1093/eurheartj/ehw334 (2016).

3 Badimon, L. \& Vilahur, G. Thrombosis formation on atherosclerotic lesions and plaque rupture. J Int Med 276, 618-632, doi:10.1111/joim.12296 (2014).

4 Andersson, C. \& Vasan, R. S. Epidemiology of cardiovascular disease in young individuals. Nat Rev Cardiol 15, 230-240, doi:10.1038/nrcardio.2017.154 (2018).

5 Elliot, C. A. \& Hamlin, M. J. Combined diet and physical activity is better than diet or physical activity alone at improving health outcomes for patients in New Zealand's primary care intervention. BMC Publ Health 18, 230, doi:10.1186/s12889-018-5152-z (2018).

6 Lim, S. S. et al. A comparative risk assessment of burden of disease and injury attributable to 67 risk factors and risk factor clusters in 21 regions, 1990-2010: a systematic analysis for the Global Burden of Disease Study 2010. Lancet 380, 22242260, doi:10.1016/s0140-6736(12)61766-8 (2012).

7 Ladejobi, A. O. et al. The 12-lead electrocardiogram as a biomarker of biological age. Eur Heart J - Dig Health2, 379-389, doi:10.1093/ehjdh/ztab043 (2021).

8 Attia, Z. I. et al. Age and Sex Estimation Using Artificial Intelligence From Standard 12-Lead ECGs. Circ Arrhythm Electrophysiol 12, e007284, doi:10.1161/circep.119.007284 (2019). 
medRxiv preprint doi: https://doi.org/10.1101/2021.12.08.21267378; this version posted December 8, 2021. The copyright holder for this preprint (which was not certified by peer review) is the author/funder, who has granted medRxiv a license to display the preprint in perpetuity.

All rights reserved. No reuse allowed without permission.

2969 Ball, R. L., Feiveson, A. H., Schlegel, T. T., Starc, V. \& Dabney, A. R. Predicting

297 "heart age" using electrocardiography. J Pers Med 4, 65-78, doi:10.3390/jpm4010065

$298 \quad$ (2014).

29910 Lima, E. M. et al. Deep neural network-estimated electrocardiographic age as a

300 mortality predictor. Nature Commun 12, 5117, doi:10.1038/s41467-021-25351-7

$301 \quad(2021)$.

30211 Lopez-Gonzalez, A. A. et al. Effectiveness of the Heart Age tool for improving

303 modifiable cardiovascular risk factors in a Southern European population: a

304 randomized trial. Eur J Prev Cardiol 22, 389-396, doi:10.1177/2047487313518479

$305 \quad$ (2015).

30612 Soureti, A., Hurling, R., Murray, P., van Mechelen, W. \& Cobain, M. Evaluation of a

307 cardiovascular disease risk assessment tool for the promotion of healthier lifestyles.

308 Eur J Cardiovasc Prev Rehab 17, 519-523, doi:10.1097/HJR.0b013e328337ccd3

$309 \quad$ (2010).

31013 Groenewegen, K. A. et al. Vascular age to determine cardiovascular disease risk: A

311 systematic review of its concepts, definitions, and clinical applications. Eur J Prev

$312 \quad$ Cardiol 23, 264-274, doi:10.1177/2047487314566999 (2016).

31314 Parkes, G., Greenhalgh, T., Griffin, M. \& Dent, R. Effect on smoking quit rate of

314 telling patients their lung age: the Step2quit randomised controlled trial. BMJ 336,

$315 \quad$ 598-600, doi:10.1136/bmj.39503.582396.25 (2008).

31615 Maanja, M. et al. The electrical determinants of increased wall thickness and mass in

317 left ventricular hypertrophy. J Electrocardiol 58, 80-86,

318 doi:10.1016/j.jelectrocard.2019.09.024 (2020).

31916 Schlegel, T. T. et al. Accuracy of advanced versus strictly conventional 12-lead ECG

320 for detection and screening of coronary artery disease, left ventricular hypertrophy and 
left ventricular systolic dysfunction. BMC Cardiovasc Disord 10, 28, doi:10.1186/1471-2261-10-28 (2010).

32317 Johnson, K. et al. Advanced Electrocardiography Identifies Left Ventricular Systolic Dysfunction in Non-Ischemic Cardiomyopathy and Tracks Serial Change over Time. $J$ Cardiovasc Dev Dis 2, 93-107, doi:10.3390/jcdd2020093 (2015).

Gladding, P. A., Hewitt, W. \& Schlegel, T. T. Going deep with ecg and aortic stenosis: Touchdown or incomplete pass? J Am Heart Assoc 9, e016193-e016193,

19 The Lancet Respiratory Medicine, L. R. M. Opening the black box of machine learning. Lance Respir Med 6, 801-801, doi:10.1016/S2213-2600(18)30425-9 (2018). artery disease alters ventricular repolarization dynamics in type 2 diabetes. Pacing Clin Electrophysiol 28 Suppl 1, S178-181, doi:10.1111/j.1540-8159.2005.00076.x (2005). ventricular volumes and ejection fraction by automated gated myocardial SPECT versus cardiovascular magnetic resonance. Clin Physiol Funct Imaging25, 135-141, doi:10.1111/j.1475-097X.2005.00599.x (2005). reversible perfusion defects during adenosine myocardial perfusion imaging. $J$ Electrocardiol40, 510-514, doi:10.1016/j.jelectrocard.2007.03.242 (2007).

34223 Lang, R. M. et al. Recommendations for cardiac chamber quantification by echocardiography in adults: an update from the American Society of 
34624 Yamazaki, T., Froelicher, V. F., Myers, J., Chun, S. \& Wang, P. Spatial QRS-T angle

347 predicts cardiac death in a clinical population. Heart rhythm 2, 73-78,

$348 \quad$ doi:10.1016/j.hrthm.2004.10.040 (2005).

34925 Fayn, J., Rubel, P., Pahlm, O. \& Wagner, G. S. Improvement of the detection of

350 myocardial ischemia thanks to information technologies. Int J Cardiol 120, 172-180,

351 doi:10.1016/j.ijcard.2006.09.025 (2006).

35226 Kardys, I. et al. Spatial QRS-T angle predicts cardiac death in a general population.

353 European heart journal24, 1357-1364, doi:10.1016/S0195-668X(03)00203-3 (2003).

35427 Horinaka, S. et al. Ventricular gradient variability. New ECG method for detection of

$355 \quad$ ischemic heart disease. J Electrocardiol 28, 177-183, doi:10.1016/S0022-

$356 \quad 0736(05) 80255-9(1995)$.

35728 Kors, J. A., van Herpen, G., Sittig, A. C. \& van Bemmel, J. H. Reconstruction of the

358 Frank vectorcardiogram from standard electrocardiographic leads: diagnostic

359 comparison of different methods. Eur Heart J 11, 1083-1092 (1990).

36029 Zabel, M. et al. Analysis of T-wave morphology from the 12-lead electrocardiogram

361 for prediction of long-term prognosis in male US veterans. Circulation $\mathbf{1 0 5}, 1066-$

362 1070, doi:10.1161/hc0902.104598 (2002).

36330 Okin, P. M. et al. Repolarization Abnormality for Prediction of All-Cause and

364 Cardiovascular Mortality in American Indians: The Strong Heart Study. J Cardiovasc

365 Electrophysiol 16, 945-951, doi:10.1111/j.1540-8167.2005.40808.x (2005).

36631 Priori, S. G. et al. Evaluation of the spatial aspects of T-wave complexity in the long-

367 QT syndrome. Circulation 96, 3006-3012, doi:10.1161/01.CIR.96.9.3006 (1997).

36832 Chhabra, L., Devadoss, R., Chaubey, V. K. \& Spodick, D. H. Interatrial Block in the

369 Modern Era. Curr Cardiol Rev10, 181-189,

$370 \quad$ doi:10.2174/1573403X10666140514101748 (2014). 
37133 Lindow, T. \& Lindqvist, P. The Prevalence of Advanced Interatrial Block and Its

372 Relationship to Left Atrial Function in Patients with Transthyretin Cardiac

$373 \quad$ Amyloidosis. J Clin Med 10, doi:10.3390/jcm10132764 (2021).

37434 Rautaharju, P. M., Mason, J. W. \& Akiyama, T. New age- and sex-specific criteria for 375 QT prolongation based on rate correction formulas that minimize bias at the upper 376 normal limits. Int J Cardiol 174, 535-540, doi:10.1016/j.ijcard.2014.04.133 (2014).

37735 Shah, S. R., Park, K. \& Alweis, R. Long QT Syndrome: A Comprehensive Review of 378 the Literature and Current Evidence. Curr Prob Cardiol 44, 92-106, 379 doi:10.1016/j.cpcardiol.2018.04.002 (2019).

38036 Nielsen, J. B. et al. Risk prediction of cardiovascular death based on the QTc interval: 381 evaluating age and gender differences in a large primary care population. Eur Heart J $382 \quad 35,1335-1344$, doi:10.1093/eurheartj/ehu081 (2014).

38337 Goorakani, Y. et al. Correlation of resting heart rate with anthropometric factors and 384 serum biomarkers in a population-based study: Fasa PERSIAN cohort study. BMC 385 Cardiovas Disord 20, 319-319, doi:10.1186/s12872-020-01594-y (2020).

38638 Ogliari, G. et al. Resting heart rate, heart rate variability and functional decline in old 387 age. Can Med Assoc J 187, E442-e449, doi:10.1503/cmaj.150462 (2015).

38839 Morcet, J. F., Safar, M., Thomas, F., Guize, L. \& Benetos, A. Associations between 389 heart rate and other risk factors in a large French population. J Hyperten s17, 1671390 1676, doi:10.1097/00004872-199917120-00003 (1999).

39140 Evans, J. G., Prior, I. A. \& Tunbridge, W. M. Age-associated change in QRS axis: 392 intrinsic or extrinsic ageing? Gerontology28, 132-137, doi:10.1159/000212523 (1982). 
medRxiv preprint doi: https://doi.org/10.1101/2021.12.08.21267378; this version posted December 8, 2021. The copyright holder for this preprint (which was not certified by peer review) is the author/funder, who has granted medRxiv a license to display the preprint in perpetuity.

All rights reserved. No reuse allowed without permission.

39441 Bergfeldt, L. et al. Spatial peak and mean QRS-T angles: A comparison of similar but

395 different emerging risk factors for cardiac death. J Electrocardiol61, 112-120,

396 doi:10.1016/j.jelectrocard.2020.05.013 (2020).

39742 Ringborn, M. M. D. et al. Comparison of high-frequency QRS components and ST-

398 segment elevation to detect and quantify acute myocardial ischemia. J Electrocardiol

$399 \quad$ 43, 113-120, doi:10.1016/j.jelectrocard.2009.11.009 (2010).

$40043 \quad$ Trägårdh, E., Pahlm, O., Wagner, G. S. \& Pettersson, J. Reduced high-frequency QRS

401 components in patients with ischemic heart disease compared to normal subjects. $J$

402 Electrocardiol 37, 157-162, doi:10.1016/j.jelectrocard.2004.02.004 (2004).

40344 Schlegel, T. T. et al. Real-Time 12-Lead High-Frequency QRS Electrocardiography

404 for Enhanced Detection of Myocardial Ischemia and Coronary Artery Disease. Mayo

$405 \quad$ Clin Proc 79, 339-350, doi:10.4065/79.3.339 (2004).

40645 Yoon, C. H., Torrance, R. \& Scheinerman, N. Machine learning in medicine: should

407 the pursuit of enhanced interpretability be abandoned? J Med Ethics,

408 doi:10.1136/medethics-2020-107102 (2021).

$40946 \quad$ Brisk, R. et al. The effect of confounding data features on a deep learning algorithm to

410 predict complete coronary occlusion in a retrospective observational setting. Eur

411 Heart J - Dig Health 2, 127-134, doi:10.1093/ehjdh/ztab002 (2021).

41247 Siontis, K. C. et al. Use of Artificial Intelligence Tools Across Different Clinical

413 Settings: A Cautionary Tale. Circ Cardiovasc Qual Outcomes14, e008153,

414 doi:10.1161/circoutcomes.121.008153 (2021).

415

416

417 
medRxiv preprint doi: https://doi.org/10.1101/2021.12.08.21267378; this version posted December 8, 2021. The copyright holder for this preprint (which was not certified by peer review) is the author/funder, who has granted medRxiv a license to display the preprint in perpetuity.

All rights reserved. No reuse allowed without permission.

Table 1. Baseline characteristics

\begin{tabular}{lccccc}
\hline & $\begin{array}{c}\text { All } \\
(\mathrm{n}=2,771)\end{array}$ & $\begin{array}{c}\text { Healthy } \\
(\mathrm{n}=1,682)\end{array}$ & $\begin{array}{c}\text { Subjects at } \\
\text { CV risk } \\
(\mathrm{n}=305)\end{array}$ & $\begin{array}{c}\text { Patients with } \\
\text { CV disease } \\
(\mathrm{n}=784)\end{array}$ & $\mathrm{p}$ \\
\hline Age, years & $46.2(16.0)$ & $38.613 .0)$ & $54.8(11.2)$ & $59.0(13.2)$ & $<0.001$ \\
Male sex, n (\%) & $1645(59.4)$ & $999(59.4)$ & $163(53.4)$ & $483(61.6)$ & 0.048 \\
$\begin{array}{l}\text { 5-minute ECG } \\
\text { Heart Age, years }\end{array}$ & $51.1(21.7)$ & $38.314 .1)$ & $61.9(13.2)$ & $74.2(15.6)$ & $<0.001$ \\
CAD, n (\%) & $421(15.2)$ & - & - & $421(53.7)$ & - \\
ICM, n (\%) & $120(4.3)$ & - & - & $120(15.3)$ & - \\
HCM, n $(\%)$ & $92(3.3)$ & - & - & $92(11.7)$ & - \\
LVH, n $(\%)$ & $96(3.5)$ & - & - & $96(12.2)$ & - \\
NICM, n $(\%)$ & $53(1.9)$ & - & - & $53(6.8)$ & - \\
\hline
\end{tabular}

Age and 5-minute ECG Heart Age are presented as mean (standard deviation).

Abbreviations: CAD: coronary artery disease; ICM: ischemic cardiomyopathy; HCM:

hypertrophic cardiomyopathy; LVH: left ventricular hypertrophy; NICM: non-ischemic cardiomyopathy

418

419

420

421

422

423

424

425

426

427

428

429

430 
Table 2. Measures included in the 10-second ECG Heart Age (male patients)

\begin{tabular}{|c|c|c|c|}
\hline Measure & Estimate & $\begin{array}{l}\text { Standard } \\
\text { error }\end{array}$ & $\mathrm{t}$ ratio \\
\hline (Intercept) & -60.575 & 2.353 & -25.73 \\
\hline Age, years & 0.820 & 0.007 & 113.73 \\
\hline $\mathrm{P}$-wave duration, $\mathrm{ms}$ & 0.288 & 0.007 & 39.99 \\
\hline Spatial QT interval, ms & 0.081 & 0.004 & 22.86 \\
\hline Heart rate, $\min ^{-1}$ & 0.242 & 0.012 & 20.02 \\
\hline QRS max amplitude in VCG lead $\mathrm{Y}, \mu \mathrm{V}$ & -0.007 & 0.000 & -18.20 \\
\hline Frontal plane QRS axis, radians & -5.834 & 0.395 & -14.75 \\
\hline $\begin{array}{l}\text { T-wave complexity, Ln } \sum(\mathrm{EV} 3: 8) /(\mathrm{EV} 1-\mathrm{EV} 2) \text {, } \\
\text { unitless }\end{array}$ & 2.152 & 0.164 & 13.12 \\
\hline $\begin{array}{l}\text { Spatial ventricular gradient minus Spatial mean } Q R S \text {, } \\
\mathrm{mV}^{*} \mathrm{~s}\end{array}$ & -55.841 & 4.464 & -12.51 \\
\hline Male sex $($ value $=1)$ & 1.996 & 0.215 & 9.27 \\
\hline QRS RMS in VCG vector magnitude lead, $\mathrm{mV}$ & 10.315 & 1.612 & 6.40 \\
\hline $\begin{array}{l}\text { QRS average spatial velocity in VCG vector } \\
\text { magnitude lead, } \mathrm{mV} / \mathrm{s}\end{array}$ & 0.106 & 0.017 & 6.30 \\
\hline $\begin{array}{l}\text { Portion of QRS loop in posterior superior quadrant of } \\
\text { left sagittal plane by VCG, } \%\end{array}$ & 0.033 & 0.009 & 3.55 \\
\hline
\end{tabular}


medRxiv preprint doi: https://doi.org/10.1101/2021.12.08.21267378; this version posted December 8, 2021. The copyright holder for this preprint (which was not certified by peer review) is the author/funder, who has granted medRxiv a license to display the preprint in perpetuity.

All rights reserved. No reuse allowed without permission.

Table 3. Measures included in the 10-second ECG Heart Age (female patients)

\begin{tabular}{|c|c|c|c|}
\hline Measure & Estimate & $\begin{array}{l}\text { Standard } \\
\text { error }\end{array}$ & t ratio \\
\hline (Intercept) & -70.477 & 2.662 & -26.47 \\
\hline Age, years & 0.850 & 0.008 & 104.26 \\
\hline $\mathrm{P}$-wave duration, $\mathrm{ms}$ & 0.331 & 0.008 & 40.73 \\
\hline Spatial QT interval, ms & 0.095 & 0.004 & 23.58 \\
\hline Heart rate, $\min ^{-1}$ & 0.281 & 0.014 & 20.57 \\
\hline QRS max amplitude in VCG lead $\mathrm{Y}, \mu \mathrm{V}$ & -0.009 & 0.000 & -18.54 \\
\hline Frontal plane QRS axis, radians & -6.354 & 0.447 & -14.21 \\
\hline $\begin{array}{l}\text { Spatial ventricular gradient minus Spatial mean QRS, } \\
\mathrm{mV}^{*} \mathrm{~s}\end{array}$ & -67.642 & 5.049 & -13.40 \\
\hline $\begin{array}{l}\text { T-wave complexity, Ln } \sum(\mathrm{EV} 3: 8) /(\mathrm{EV} 1-\mathrm{EV} 2) \text {, } \\
\text { unitless }\end{array}$ & 2.359 & 0.185 & 12.72 \\
\hline QRS RMS in VCG vector magnitude lead,mV & 11.701 & 1.822 & 6.42 \\
\hline $\begin{array}{l}\text { QRS average spatial velocity in VCG vector magnitude } \\
\text { lead, } \mathrm{mV} / \mathrm{s}\end{array}$ & 0.116 & 0.019 & 6.10 \\
\hline $\begin{array}{l}\text { Portion of QRS loop in posterior superior quadrant of } \\
\text { left sagittal plane by VCG, \% }\end{array}$ & 0.034 & 0.010 & 3.22 \\
\hline
\end{tabular}
432 
439 Figure 1. Left panel: Scatter plot showing the relation between the 10-second ECG Heart Age

440 and the 5-minute ECG Heart Age in all participants. The $\mathrm{R}^{2}$ value was $0.94(\mathrm{p}<0.001)$. Right

441 panel: Bland-Altman plot showing the difference between the 10-second and 5-minute ECG

442 Heart Age in relation to the mean of both ECG Heart Ages. The agreement between methods

443 is strong, with minimal deviation from the identity line (dashed) or bias $(0.0 \pm 5.2$ years).

Figure 2.

446 Panel A: The difference between the 10-second ECG Heart Age and chronological age in 447 healthy subjects (left, dark green), subjects at cardiovascular (CV) risk (middle, light blue), 448 and patients with CV disease (right, yellow). On average, there is no difference between ECG 449 Heart Age and chronological age in healthy subjects. ECG Heart Age is higher in subjects at $450 \quad \mathrm{CV}$ risk, and highest for those with overt CV disease.

451 Panel B: Scatter plots showing the relationship between the 10-second ECG Heart Age and 452 chronological age in healthy subjects (left, dark green), subjects at CV risk (middle, light 453 blue), and patients with CV disease (right, yellow). The dashed diagonal line is the identity line, i.e. indicating no difference between ECG Heart Age and chronological age.

Figure 3. Example of the transparency and explainability of the ECG Heart Age from two subjects with equal chronological age but different ECG Heart Ages, illustrated by a commensurately aged female heart, but a disproportionately aged male heart. The ECG measures for each of the two patients are shown in the table in the middle of the figure, presented in the order of the relative strength (strongest first, based on t ratio [not shown]) of contribution to the ECG Heart Age. Notably, P-wave duration is markedly different between these two patients, and heart rate is higher for the male than the female, helping drive the 
medRxiv preprint doi: https://doi.org/10.1101/2021.12.08.21267378; this version posted December 8, 2021. The copyright holder for this preprint

(which was not certified by peer review) is the author/funder, who has granted medRxiv a license to display the preprint in perpetuity.

All rights reserved. No reuse allowed without permission.

464 female, and the difference between the spatial ventricular gradient and the spatial mean QRS

465 in the female is also larger, likely due to preserved T-wave amplitudes, contributing to her

466 relatively younger ECG Heart Age. Furthermore, likely due to ischemic myocardial injuries,

467 T-wave complexity is increased in the male, suggesting thatincreased myocardial

468 repolarization heterogeneity also contributes to driving ECG Heart Age higher in the male, in

469 spite of his shorter QT interval. 

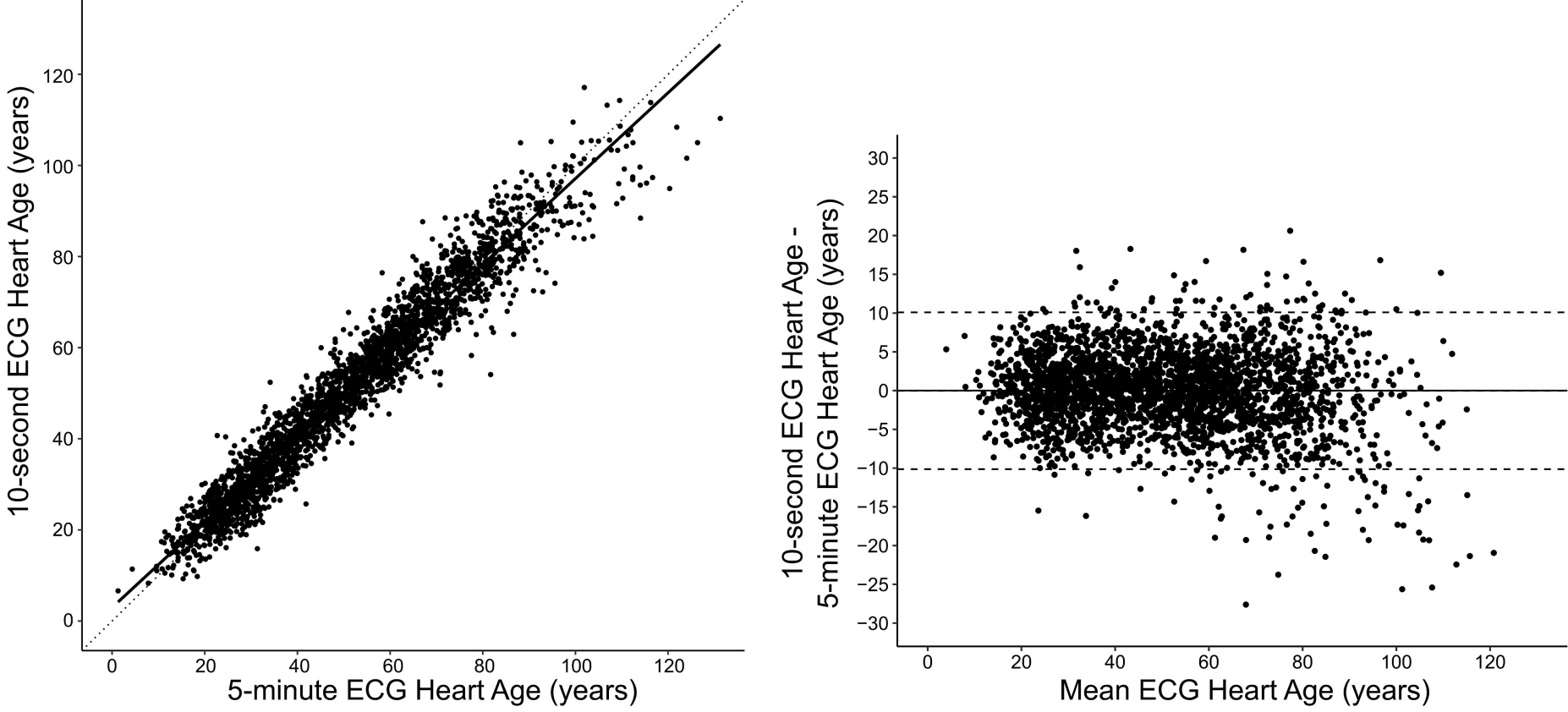


\section{$p<0.001$}

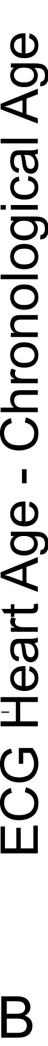

$p<0.001$

क10

(ำ

$\geqslant$

20
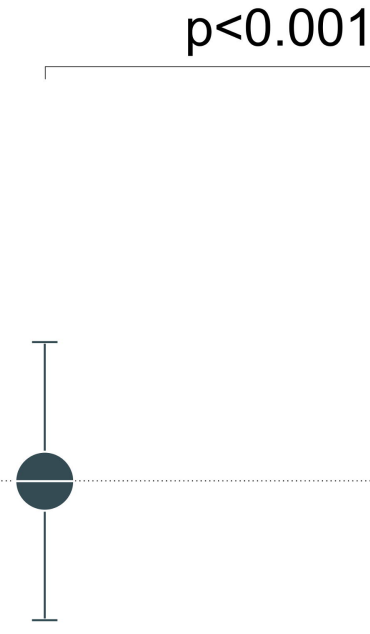

$-10$

Health

CV Risk Factors

CV Disease
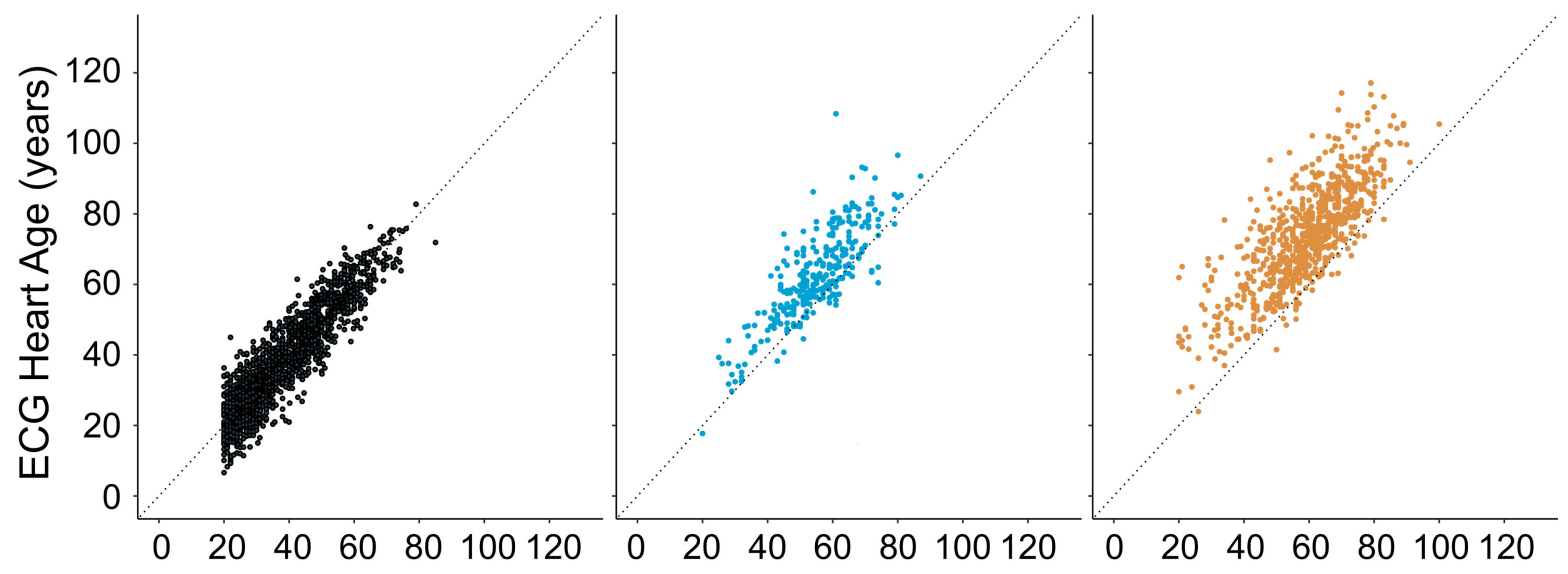

Chronological age (years) 
